\title{
Wnt signal transduction pathways: modules, development and evolution
}

\author{
Losiana Nayak¹, Nitai P. Bhattacharyya ${ }^{2,3}$ and Rajat K. De ${ }^{1^{*}}$ \\ From IEEE International Conference on Bioinformatics and Biomedicine 2015 \\ Washington, DC, USA. 9-12 November 2015
}

\begin{abstract}
Background: Wnt signal transduction pathway (Wnt STP) is a crucial intracellular pathway mainly due to its participation in important biological processes, functions, and diseases, i.e., embryonic development, stem-cell management, and human cancers among others. This is why Wnt STP is one of the highest researched signal transduction pathways. Study and analysis of its origin, expansion and gradual development to the present state as found in humans is one aspect of Wnt research. The pattern of development and evolution of the Wnt STP among various species is not clear till date. A phylogenetic tree created from Wnt STPs of multiple species may address this issue.

Results: In this respect, we construct a phylogenetic tree from modules of Wnt STPs of diverse species. We term it as the 'Module Tree'. A module is nothing but a self-sufficient minimally-dependent subset of the original Wnt STP. Authenticity of the module tree is tested by comparing it with the two reference trees.

Conclusions: The module tree performs better than an alternative phylogenetic tree constructed from pathway topology of Wnt STPs. Moreover, an evolutionary emergence pattern of the Wnt gene family is created and the module tree is tallied with it to showcase the significant resemblances.
\end{abstract}

Keywords: Module tree, Modularization algorithm, Wnt signal transduction pathway, Pathway phylogeny, Pathway development, Wht gene family evolution

\section{Background}

Wnts are secreted lipid-modified glycoproteins rich with cysteine amino acid. They bind to Frizzled seventransmembrane-spanning receptors (FZDs) along with co-receptor LRPs (Lipoprotein Receptor-related Proteins) and initiate a cascaded series of steps, which altogether are known as the Wnt STP $[1,2]$. Wnt STP is involved in many crucial cellular functions, i.e., regulation of fate determination, proliferation, differentiation, migration and apoptosis of cells [3, 4]. In adult organisms, Wnts maintain stem cell like fates in the intestinal epithelium [5], skin [6], and hematopoietic cells [7], which entitles this pathway with immense possibility in regeneration and specification $[8,9]$, differentiation and wound healing $[10,11]$, and induced tissue creation [12] among others. A number of

*Correspondence: rajat@isical.ac.in

1 Indian Statistical Institute, 203 Barrackpore Trunk Road, 700108 Kolkata, India Full list of author information is available at the end of the article studies has been dedicated to analyze the specific details of Wnt STPs in a few model organisms [13-15]. On the contrary, only a few investigations have been initiated to understand how this pathway itself has developed and evolved $[16,17]$. A phylogenetic tree constructed from modules may facilitate better understanding of Wnt STP development and evolution.

A module is a subset of a pathway/network, which is/tends to be self-sufficient and have minimal dependency on the rest part of the network. We divide a network into a number of modules, because complexity and size of each module is less than that of the entire pathway. So it becomes easy to study and understand the entire network by parts. A better operational view of a pathway can be had by analyzing its modules $[18,19]$. Modules can also be compared among two species and their dissimilarity can be used as a measure of their distance. These distances among a set of species can be utilized to construct a phylogenetic tree namely the "Module Tree" [20]. 
Phylogenetic trees can also be generated from signal transduction pathway by their size [21, 22], similarity of the nucleotide sequences [23], amino acid sequences [24], enzyme sequences [25], and protein structural classification [26]. Some other ways of alignment are based on functional similarity of the enzymes [27] and proteins [28], enzyme hierarchy and gene ontology [29], chemical structures or compound similarity [30]. Presence of common topological structures, i.e., graphlets or subpathways [31], and presence or absence of pathways in an entire pathway repertoire [32] can also be utilized for pathway comparison and subsequently for phylogenetic tree construction.

Here, we have considered Wnt STPs of 48 species (Table 1) ranging from placozoans to humans to construct our module data based phylogenetic tree, i.e., module tree. As an extension, we have also considered Wnt STPs of 99 species (Table 4), later found in an updated KEGG/Pathway database [33]. Tables 1 and 4 list total number of genes present in the species-specific Wnt STPs, total number of modules created from a pathway, and the type and source of $18 \mathrm{~S}$ rRNA sequence used [G: GenBank accession number (Complete sequence), G-P: GenBank accession number (Partial Sequence), G-S: GenBank accession number of predicted 18S rRNA sequence as given in SILVA database [34], and S-E: Sequence taken from Stage and EickBush, 2007 [35].

In this article we have created two alternative phylogenetic trees, i.e., the module tree and the pathway tree, to study development of Wnt STPs. These trees have been created by considering modules and whole pathway topology of species specific Wnt STPs respectively. Four species sets corresponding to 99, 48, 29 and 12 species have been considered. These phylogenetic trees represent development of the Wnt STP obtained at module and pathway level. They were compared with the NCBI taxonomy and 18S rRNA trees for their quality assessment in representing development of Wnt STP. The phylogenetic trees have been created with MEGA version 4.0.2 [36]. In addition, an evolutionary emergence pattern of the Wnt gene family has been constructed and the module tree from 48 species-specific Wnt STPs has been tallied with it to showcase the resemblances. A large diverse species set (99 species) has been avoided as it involves a set of different extensive phylum specific studies which is beyond the scope of this manuscript.

\section{Data}

Species-specific Wnt STPs in KEGG/Pathway database [33] has been taken as raw data (Table 1). The pathway specific interactions were extracted from their corresponding KGML (KEGG Markup Language) files. The database uses a unique three (four in some cases) letter code for each species along with their biological and common names (wherever applicable), i.e., 'hsa' for $H$. sapiens (human). These three/four letter codes have been used extensively in this manuscript.

\section{$18 S$ rRNA Sequence Data}

$18 \mathrm{~S}$ rRNA is a component of small eukaryotic ribosomal subunit (40S). 18S rRNA sequences have slow evolutionary rate. Hence, they are widely used in reconstructing the evolutionary history and ancient divergences of organisms. Here, most of the $18 \mathrm{~S}$ rRNA sequences have been taken from GenBank [37] for construction of the $18 \mathrm{~S}$ rRNA tree. With a simple search dialogue of "- [organism] AND 18S ribosomal RNA [keyword] NOT (partial)", the sequence of interest can be extracted easily. If complete sequences are not available, the "NOT (partial)" dialogue can be omitted and a search for partial sequences can be done.

We have found 28 complete and 11 partial $18 \mathrm{~S}$ rRNA nucleotide sequences for which GenBank accession numbers are listed in Table 1. Eight sequences have been taken from the SILVA comprehensive ribosomal RNA databases (http://www.arb-silva.de/). SILVA [34] provides quality checked and aligned free ribosomal RNA sequence data for academic use. It has datasets of aligned small (16S/18S, SSU) and large subunit (23S/28S, LSU) rRNA sequences for Bacteria, Archaea and Eukarya. We have taken sequences from the SSU r106 database and their respective GenBank accession numbers are given in Table 1. 18S rRNA sequence of D. grimshawi has been taken from Stage and Eickbush, 2007 [35] as it is not available in GenBank or SILVA.

\section{Methods}

Here we describe the methodology (Fig. 1) involved in creating phylogenetic trees from species specific Wnt STPs, taxonomy information from NCBI and 18S rRNA sequences. We have considered two different sets of factors to do system level development analysis of speciesspecific Wnt STPs. Our aim is to know the similarity in percentage of our constructed phylogenetic trees (constructed from pathway topology and modules) with respect to the standard evolutionary trees (18S rRNA and NCBI taxonomy tree).

\section{Module tree method}

The module tree has been generated solely based on one-to-one mapping of members present in modules of different species-specific Wnt STPs. A module can be defined as a subset of a STP that tends to be self-sufficient by maintaining minimal dependency on the remaining part of the STP. Modules have been created by the Modularization Algorithm developed earlier by the authors [18] based on a user defined factor $c$. The lowest possible $c$-value is always 1 . The upper limit of $c$-value is the 
Table 1 A list of 48 species-specific Wnt signaling pathways and their respective 18S rRNA Reference ids

\begin{tabular}{|c|c|c|c|c|c|c|}
\hline $\begin{array}{l}\text { Sl. } \\
\text { No. }\end{array}$ & $\begin{array}{l}\text { KEGG } \\
\text { code }\end{array}$ & $\begin{array}{l}\text { Binomial } \\
\text { nomenclature }\end{array}$ & $\begin{array}{l}\text { Common } \\
\text { name }\end{array}$ & $\begin{array}{l}\text { No. of } \\
\text { genes }\end{array}$ & $\begin{array}{c}\text { No. of } \\
\text { modules }\end{array}$ & $\begin{array}{r}18 \mathrm{~S} \text { rRNA } \\
\text { sequence id }\end{array}$ \\
\hline 1 & aag & A. aegypti & $\begin{array}{l}\text { Yellow fever } \\
\text { mosquito }\end{array}$ & 34 & 6 & U65375 [G] \\
\hline 2 & aga & A. gambiae & Mosquito & 31 & 6 & AM157179 [G] \\
\hline 3 & ame & A. mellifera & Honey bee & 38 & 7 & AY703484 [G-P] \\
\hline 4 & $\mathrm{aml}$ & A. melanoleuca & Giant Panda & 59 & 8 & GL196163 [G] \\
\hline 5 & api & A. pisum & Pea aphid & 32 & 6 & U27819 [G] \\
\hline 6 & bfo & B. floridae & Florida lancelet & 45 & 7 & M97571 [G] \\
\hline 7 & bmy & B. malayi & Filaria & 34 & 7 & AAQA01003643 [G-S] \\
\hline 8 & bta & B. taurus & Cow & 59 & 8 & NR_036642 [G] \\
\hline 9 & $\mathrm{cbr}$ & C. briggsae & - & 23 & 3 & FJ380929 [G] \\
\hline 10 & cel & C. elegans & Nematode & 23 & 3 & EU196001 [G-P] \\
\hline 11 & $\mathrm{cfa}$ & C. familiaris & Dog & 58 & 8 & AAEX02007663 [G-S] \\
\hline 12 & $\operatorname{cin}$ & C. intestinalis & Sea squirt & 42 & 7 & AB013017 [G-P] \\
\hline 13 & cqu & C. quinquefasciatus & $\begin{array}{l}\text { Southern house } \\
\text { mosquito }\end{array}$ & 35 & 7 & AAWU01013261 [G-S] \\
\hline 14 & dan & D. ananassae & - & 37 & 7 & XR_046314 [G] \\
\hline 15 & der & D. erecta & - & 37 & 7 & XR_046906 [G] \\
\hline 16 & dgr & D. grimshawi & - & 37 & 7 & {$[S-E]$} \\
\hline 17 & dme & D. melanogaster & Fruit fly & 37 & 7 & M21017 [G] \\
\hline 18 & dmo & D. mojavensis & - & 37 & 7 & XR_047783 [G] \\
\hline 19 & dpe & D. persimilis & - & 32 & 5 & XR_046906 [G] \\
\hline \multirow[t]{2}{*}{20} & dpo & D. pseudoobscura & - & 32 & 6 & XR_053284 [G] \\
\hline & & pseudoobscura & & & & \\
\hline 21 & dre & D. rerio & Zebrafish & 59 & 8 & AC139725 [G-S] \\
\hline 22 & dse & D. sechellia & - & 37 & 7 & XR_048770 [G] \\
\hline 23 & dsi & D. simulans & - & 22 & 5 & AY037174 [G] \\
\hline 24 & dvi & D. virilis & - & 38 & 7 & XR_049279 [G] \\
\hline 25 & dwi & D. willistoni & - & 37 & 7 & XR_049811 [G] \\
\hline 26 & dya & D. yakuba & - & 36 & 6 & XR_050457 [G] \\
\hline 27 & ecb & E. caballus & Horse & 56 & 8 & AJ311673 [G-P] \\
\hline 28 & gga & G. gallus & Chicken & 54 & 8 & M59389 [G] \\
\hline 29 & hmg & H. magnipapillata & - & 31 & 6 & HQ392522 [G-P] \\
\hline 30 & hsa & H. sapiens & Human & 60 & 8 & X03205 [G] \\
\hline 31 & isc & I. scapularis & $\begin{array}{l}\text { Black-legged } \\
\text { tick }\end{array}$ & 30 & 6 & ABJB010180167 [G-S] \\
\hline 32 & $\mathrm{mcc}$ & M. mulatta & Rhesus Monkey & 59 & 8 & FJ436026 [G-P] \\
\hline 33 & mdo & M. domestica & Opossum & 55 & 7 & AJ311676 [G-P] \\
\hline 34 & $\mathrm{mmu}$ & M. musculus & Mouse & 60 & 8 & X00686 [G] \\
\hline 35 & nve & N. vectensis & Sea anemone & 33 & 6 & AF254382 [G] \\
\hline 36 & nvi & N. vitripennis & Jewel wasp & 38 & 7 & GQ410677 [G-P] \\
\hline 37 & oaa & O. anatinus & Platypus & 47 & 7 & AJ311679 [G-P] \\
\hline 38 & phu & $\begin{array}{l}\text { P. humanus } \\
\text { corporis }\end{array}$ & $\begin{array}{l}\text { Human body } \\
\text { louse }\end{array}$ & 37 & 7 & FJ267399 [G-P] \\
\hline 39 & ptr & P. troglodytes & Chimpanzee & 58 & 8 & AADA01268803 [G-S] \\
\hline
\end{tabular}


Table 1 A list of 48 species-specific Wnt signaling pathways and their respective 185 rRNA Reference ids (Continuation)

\begin{tabular}{|c|c|c|c|c|c|c|}
\hline 40 & rno & R. norvegicus & Rat & 60 & 8 & $\mathrm{X} 01117$ [G] \\
\hline 41 & $\mathrm{smm}$ & S. mansoni & - & 25 & 5 & U65657 [G] \\
\hline 42 & spu & S. purpuratus & $\begin{array}{l}\text { Purple } \\
\text { sea urchin }\end{array}$ & 41 & 6 & L28055 [G] \\
\hline 43 & SSC & S. scrofa & Pig & 21 & 4 & AY265350 [G] \\
\hline 44 & tad & T. adhaerens & - & 23 & 6 & Z22783 \\
\hline 45 & tca & T. castaneum & $\begin{array}{l}\text { Red flour } \\
\text { beetle }\end{array}$ & 37 & 7 & HM156711 [G \\
\hline 46 & $\operatorname{tgu}$ & T. guttata & Zebra finch & 47 & 7 & ABQF01063677 [G- \\
\hline 47 & xla & X. laevis & $\begin{array}{l}\text { African } \\
\text { clawed frog }\end{array}$ & 51 & 8 & X04025 \\
\hline 48 & xtr & $X$. tropicalis & $\begin{array}{l}\text { Western } \\
\text { clawed frog }\end{array}$ & 57 & 8 & AAMC01 103672 [G \\
\hline
\end{tabular}

Notations: G: GenBank accession number (Complete sequence), G-P: GenBank accession number (Partial Sequence), G-S: GenBank accession number of predicted 18S rRNA sequence as given in SILVA database (Pruesse et al. 2007), S-E: Sequence taken from (Stage and Eickbush 2007)

highest total degree of a node present in the considered network. Detailed working procedure of the algorithm can be obtained by following the pseudo-code furnished here.

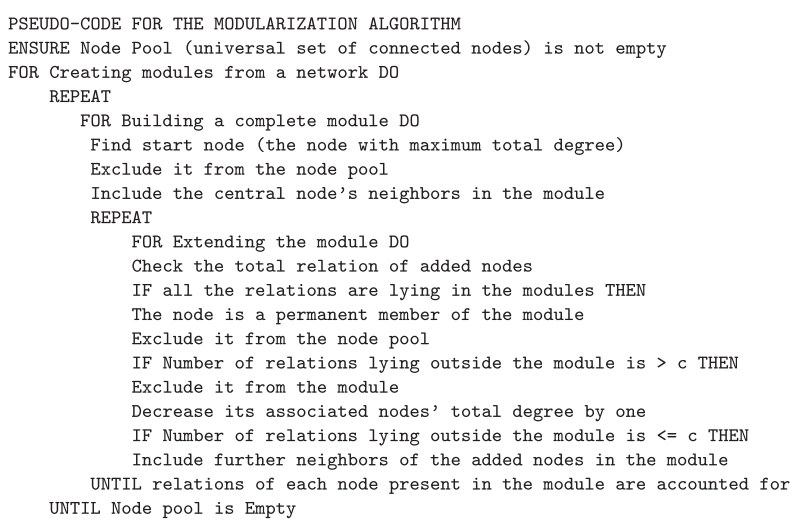

Number of modules found in a pathway depends on its size and complexity. Hence, varying number of modules can be found for different species-specific Wnt signal transduction pathways. Presence, absence or modification (increase/decrease due to addition/deletion of nodes) found in modules of a pair of species-specific pathways represent their distance. This approach is inspired by the NCE method described by Heymans and Singh, 2003 [27]. NCE method detects number of common enzymes between two pathways and tries to guess similarity based on that number. Here, rather than considering number of common enzymes, we are calculating number of common nodes present in the corresponding module of two species-specific Wnt signal transduction pathways. The score is then normalized by dividing it with the total number of non-redundant nodes present in both the

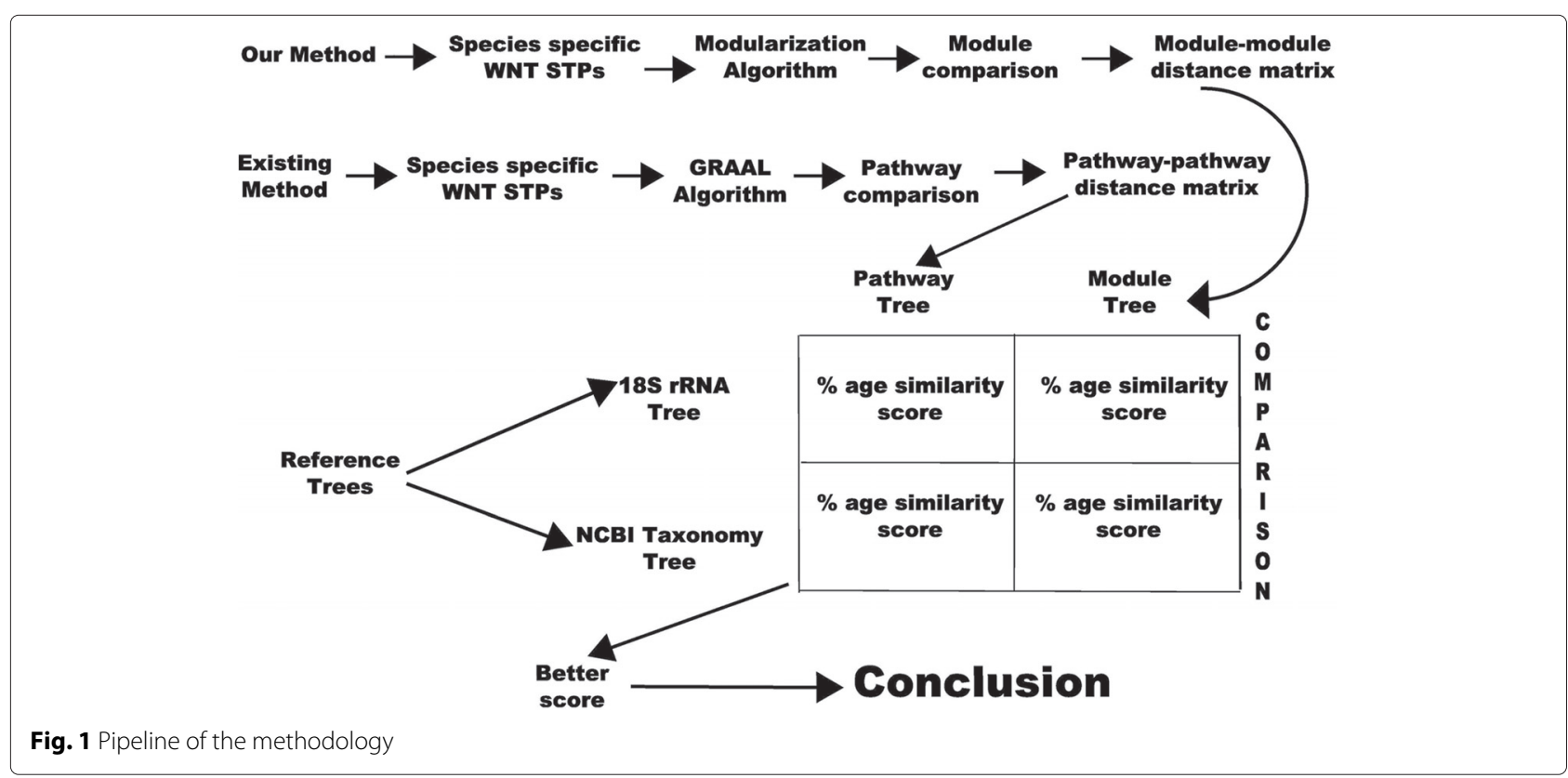


species-specific modules. Hence, if pathway of species $x$ has $m_{1}$ modules and pathway of species $y$ has $m_{2} \bmod -$ ules, we will get a similarity matrix of order $m_{1} \times m_{2}$. Each element of the matrix represents similarity score between two different modules belonging to two different species (Eq. 1). Let $M_{1}$ be a module of species $x$, i.e., $M_{1}$ is the set of all the nodes in the module. Similarly, in a species $y, M_{2}$ is a set of nodes that constitute a module. The score of similarity $\operatorname{Sim}\left(M_{1}, M_{2}\right)$ between module $M_{1}$ of species $x$ and module $M_{2}$ of species $y$ is defined as

$$
\operatorname{Sim}\left(M_{1}, M_{2}\right)=\left|M_{1} \cap M_{2}\right| /\left|M_{1} \cup M_{2}\right|
$$

Now the similarity $S_{M}(x, y)$ between species $x$ and $y$ is defined as

$$
S_{M}(x, y)=\sum_{i=1, j=1}^{m_{1}, m_{2}} \operatorname{Sim}\left(M_{i}, M_{j}\right) /\left(m_{1} \times m_{2}\right)
$$

Distance score $D_{M}(x, y)$ is defined as

$$
D_{M}(x, y)=1-S_{M}(x, y)
$$

These distance scores found among 48 different species are utilized for creation of the module tree. Our purpose in creating such a tree is to test its novelty in presenting the pathway's development.

\section{Pathway tree method}

We have generated the pathway tree based on topological distances among species-specific pathways. Topological distance $D_{P}(x, y)$ between two pathways of species $x$ and $y$ has been defined as $D_{P}(x, y)=1-S_{P}(x, y)$ where $S_{P}(x, y)$ has been the topological similarity between the two species-specific pathways. $S_{P}(x, y)$ has been calculated by the GRAph ALigner algorithm (GRAAL) developed by Kuchaiev et al. [21] and implemented in the GraphCrunch2 software [38]. $S_{P}(x, y)$ is nothing but Edge Correctness (EC) value between a pair of species-specific Wnt STPs. Edge correctness is the percentage of edges in the first graph that are aligned to edges in the second graph. High edge correctness means the pair of networks considered share similar topologies.

GRAAL [21] performs network alignment by using topological information based on graphlets of individual networks. Given two networks, the GRAAL algorithm (a seed-and-extend algorithm) finds an embedding of the smaller network into the larger network. It greedily aligns nodes based on their signature similarities while traversing both networks simultaneously in a breadth-first manner. Every node in the smaller network gets aligned to exactly one node in the larger one and finally a topological similarity score gets generated.

\section{8s rRNA tree method}

Standard 18S rRNA sequences (Table 1) have been used to create the $18 \mathrm{~S}$ rRNA tree as shown in Fig. 2. The evolutionary history has been inferred using the NeighborJoining method [39]. The optimal tree with the sum of branch length $=2.18407422$ has been considered. The evolutionary distances have been computed in the units of the number of base substitutions per site using the Maximum Composite Likelihood method [40]. All positions containing gaps and missing data have been eliminated only in pairwise sequence comparisons (Pairwise deletion option). A total of 2687 positions were there in the final dataset.

\section{NCBI taxonomy tree method}

The NCBI taxonomy tree (Fig. 3) has been created with the help of NCBI taxonomy database (http://www.ncbi. nlm.nih.gov/Taxonomy/CommonTree/wwwcmt.cgi) [41]. Newick format of the tree has been saved as a text tree after adding organism names in the "Taxonomy Common tree" page.

\section{Tree comparison method}

Nye et al. [42] have developed an algorithm that pairs up each branch in one phylogenetic tree with a matching branch in the second one, and finds the optimum one-to-one map between branches in the two trees in terms of a topological score. They have developed an Java applet (http://www.mas.ncl.ac.uk/ ntmwn/ phylo_comparison/pairwise.html) which enables one to explore the corresponding mapping between the phylogenetic trees interactively, and clearly highlights similar/different parts of the trees, both in terms of topology and branch length. Here, we have considered topology mainly.

Let us now describe the algorithm that compares two phylogenetic trees created from the same set of species. Given two phylogenetic trees $T_{1}$ and $T_{2}$ that share the same set of leaves $L$, the algorithm firstly assigns a score $s(i, j)$ to every pair of edges $(i, j)$ with $i \in T_{1}$ and $j \in T_{2}$. Then it pairs up branches in the two trees to optimize the overall score. This is equivalent to finding a bijection (i.e., a one-to-one and onto correspondence) $f: T_{1} \rightarrow T_{2}$ between the branches of the trees that maximizes the quantity $\sum_{i \in T_{1}} S(i, f(i))$.

\section{Results and discussions}

In this section, we describe ranks and positional significance of the species in the pathway tree (Fig. 4) and the module tree (Fig. 5). The species with similar 


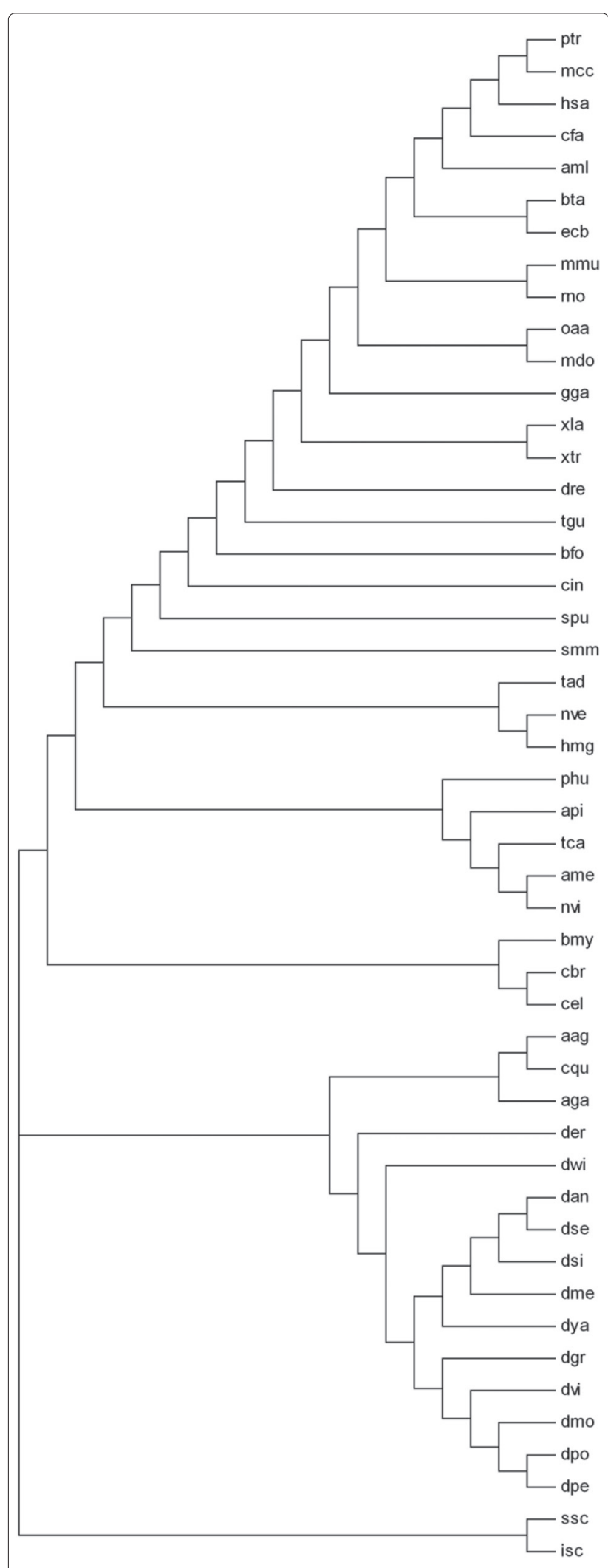

Fig. 2 The $18 \mathrm{~S}$ rRNA tree

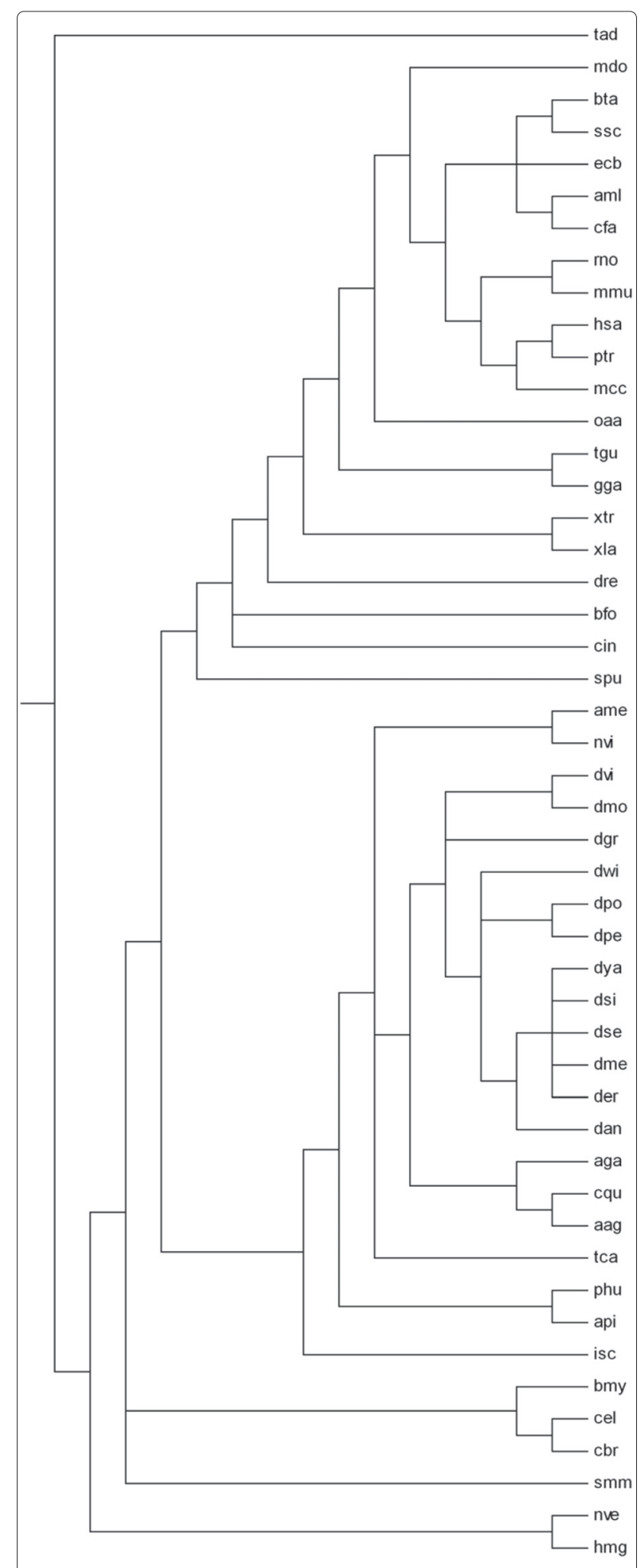

Fig. 3 The NCBI taxonomy tree 
taxonomic ranks coming under the same clade have been marked by continuous rectangles. The species coming under different clades despite having similar taxonomy have been marked by dotted rectangles. While discussing positional significance of species, we have furnished the similarities in terms of taxonomic ranks (phylum, class and others) to the lowest possible taxonomic rank. Throughout this manuscript we have used some common notations while analyzing the phylogenetic trees. The notations are listed alphabetically in Table 2.

We have compared Wnt STPs of 48 different species as provided in Table 1 for creating a module tree (Fig. 4) and a pathway tree (Fig. 5). The considered species belong to seven different phyla, most of which (21) belong to the phylum Arthropoda followed by Chordata (19), Nematoda (3), Cnidaria (2), and single species from phyla Echinodermata, Placozoa and Platyhelminthes. As expected, some species have been placed closely in the tree following their taxonomic ranks. On the other hand, we have also found some deviations.

\section{Finding a better tree}

Closely related species come under a single clade in both the module and pathway trees. In this sense, they have shown preservation of contemporary notions regarding development of species. But, they have shown numerous deviations also, when evolutionarily distant species came under a single clade or species having similar taxonomy got included in different clades. In order to put a universal measure to their quality, and to determine the better tree that represents development of Wnt STP, we have followed the concept of alternative phylogenetic tree comparison [42]. A brief description of this method of comparison is furnished in the methodology section.

We have compared the module and pathway trees with the reference trees (NCBI taxonomy tree and 18S rRNA tree). The reference trees represent phylogeny of living organisms from multiple point-of-views while the phylogenetic trees derived from species-specific Wnt STPs solely represent development of Wnt STP over the taken set of species. So a huge gap can be noticed among the two sets of phylogenetic trees in terms of similarity percentage. Still, a more similar tree is better than a less similar tree for development analysis.

The module tree has showed $42.4 \%$ topological similarity with the NCBI taxonomy tree and $42.2 \%$ similarity with the 18S rRNA tree followed by the pathway tree (38.2\% and $37.1 \%$ respectively) as given in Table 3 . Hence, the module tree has outperformed the pathway tree in representing Wnt STP development. However, among $4818 \mathrm{~S}$ rRNA sequences, 11 are partial and 8 are predicted. Did the incomplete sequences influence the $18 \mathrm{~S}$ rRNA tree (e.g. two unrelated species are clustered together because of lack of the same part of 18s rRNA sequences)? To avoid such a notion, we have repeated our protocol with a species set of 29 species (aag, aga, aml, api, bfo, bta, cbr, dan, der, dgr, dme, dmo, dpe, dpo, dse, dsi, dvi, dwi, dya, gga, hsa, mmu, nve, rno, smm, spu, ssc, tad and xla), for which complete 18S rRNA sequences are available as given in Table 1 . The module tree has also outperformed the pathway tree, for these species.

Some of the pathways in our species set comprising 48 species-specific pathways are partially known as the underlying graph structures of pathways (KEGG) are highly incomplete. Some model organisms are better studied than others. This could cause a bias and the pathwaybased graph may be more prone to this bias. To avoid such a bias, and in order to strengthen our results, we have considered Wnt STP of a smaller and more complete pathway species set of 12 (aml, bta, cfa, dre, ecb, hsa, mcc, mdo, $\mathrm{mmu}, \mathrm{ptr}$, rno and xtr). These pathways have varying number (55-60) of nodes. For this species set too, the module tree has showed maximum similarity with the NCBI taxonomy tree $(45.4 \%)$ and the $18 \mathrm{~S}$ rRNA tree $(55.4 \%)$ as given in Table 3.

The recently updated KEGG/Pathway database [33] lists 108 species-specific Wnt signaling pathways, out of which we have taken 99 pathways based on the availability of their respective $18 \mathrm{~S}$ rRNA sequences. For the remaining 9 species (P. tigris altaica, C. ferus, G. fortis, F. albicollis, P. humilis, C. cornix, F. peregrinus, C. mydas and $P$. bivittatus), we could not find their respective $18 \mathrm{~S}$ rRNA sequences. The list and details of the 99 considered species are given in Table 4. The module tree has out-performed the pathway tree for this diverse 99 species set. It has $36.3 \%$ similarity with the NCBI taxonomy tree while the pathway tree has $30.3 \%$ similarity. Moreover, the module tree has $32.4 \%$ similarity with the $18 \mathrm{~S}$ rRNA tree while the pathway tree has $26.9 \%$ similarity as given in Table 3. The NCBI taxonomy, $18 \mathrm{~S}$ rRNA, pathway and module trees for 99 species are provided in Table 4. The associated four figures for NCBI taxonomy, 18S rRNA, pathway and module trees and their respective newick formats are given in Additional file 1. The higher similarity of the module tree for all the species sets with the NCBI taxonomy and 18S rRNA trees suggests that the module tree is a better tree for studying Wnt signaling pathway development.

However evolution of Wnt gene family is a different phenomenon and the following subsections have concentrated on finding some links between the module tree for 48 species-specific pathways and the Wnt gene family evolutionary trend. The module tree of a reasonable size (48 species) has been taken to facilitate ease of linking 


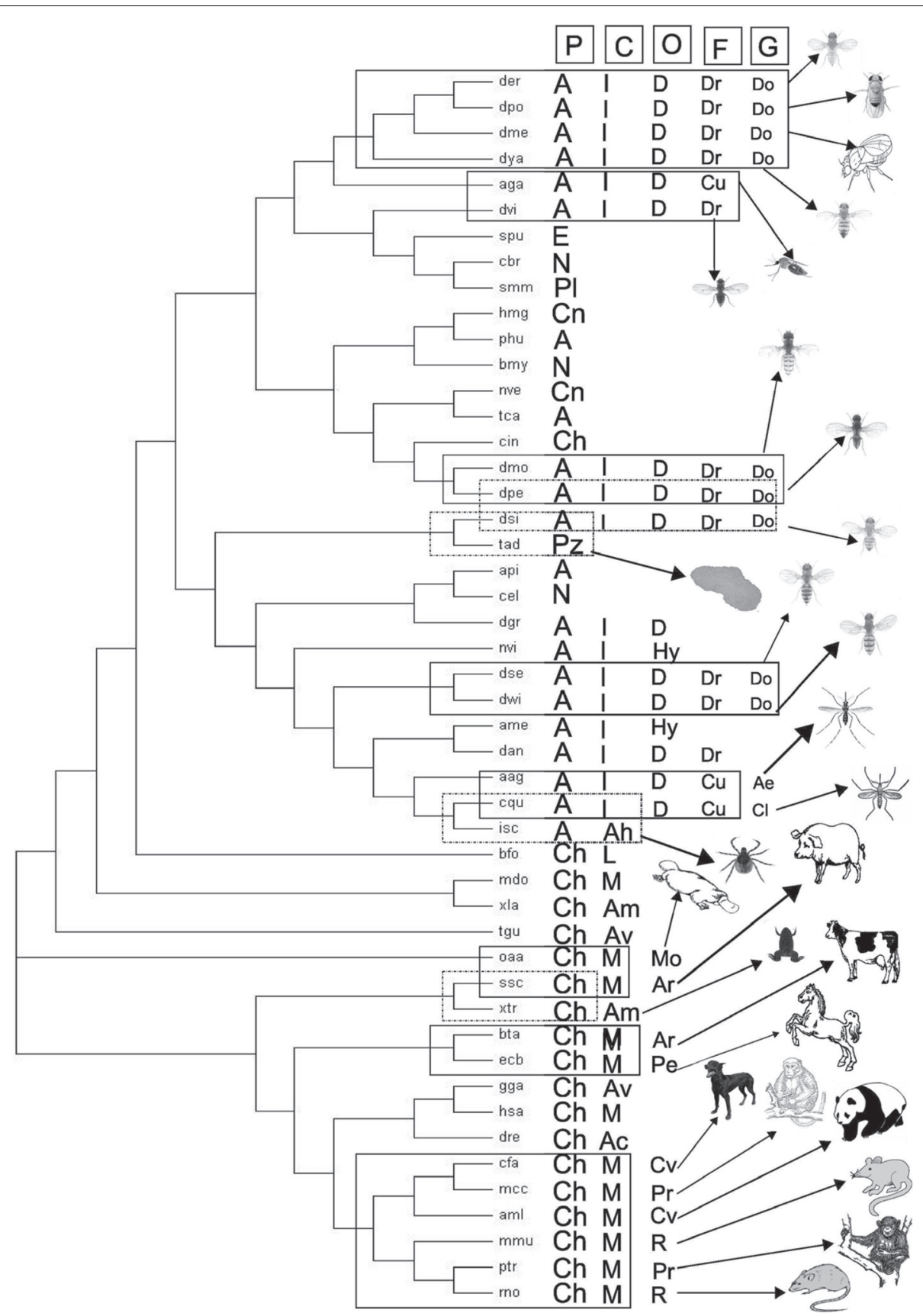

Fig. 4 The module tree. It is constructed from 48 species. The notations used in the figure are listed in Table 2

it with the evolutionary trend. A large diverse species set (99 species) has been avoided as it involves a set of different extensive phylum specific studies which is beyond the scope of this manuscript.

\section{Evolution of Wnts}

The origin of Wnts and emergence of multicellularity are associated events. The comb jellies, sponges and placozoans of prebilaterian lineage possess a few Wnt genes [43]. But the Most Recent Common Ancestor (MRCA) of Cnidaria and Bilateria is believed to have an enormous expansion in ligand diversity [44], resulting in the origin of 11 of the 13 contemporary subfamilies. Wnt genes constitute a large family of lipid-modified, secreted signaling molecules. they are found to be highly conserved across the metazoan kingdom. Orthologs of individual Wnts have been found in animal species ranging from Cnidaria and Porifera (sponges) to flies and vertebrates. 


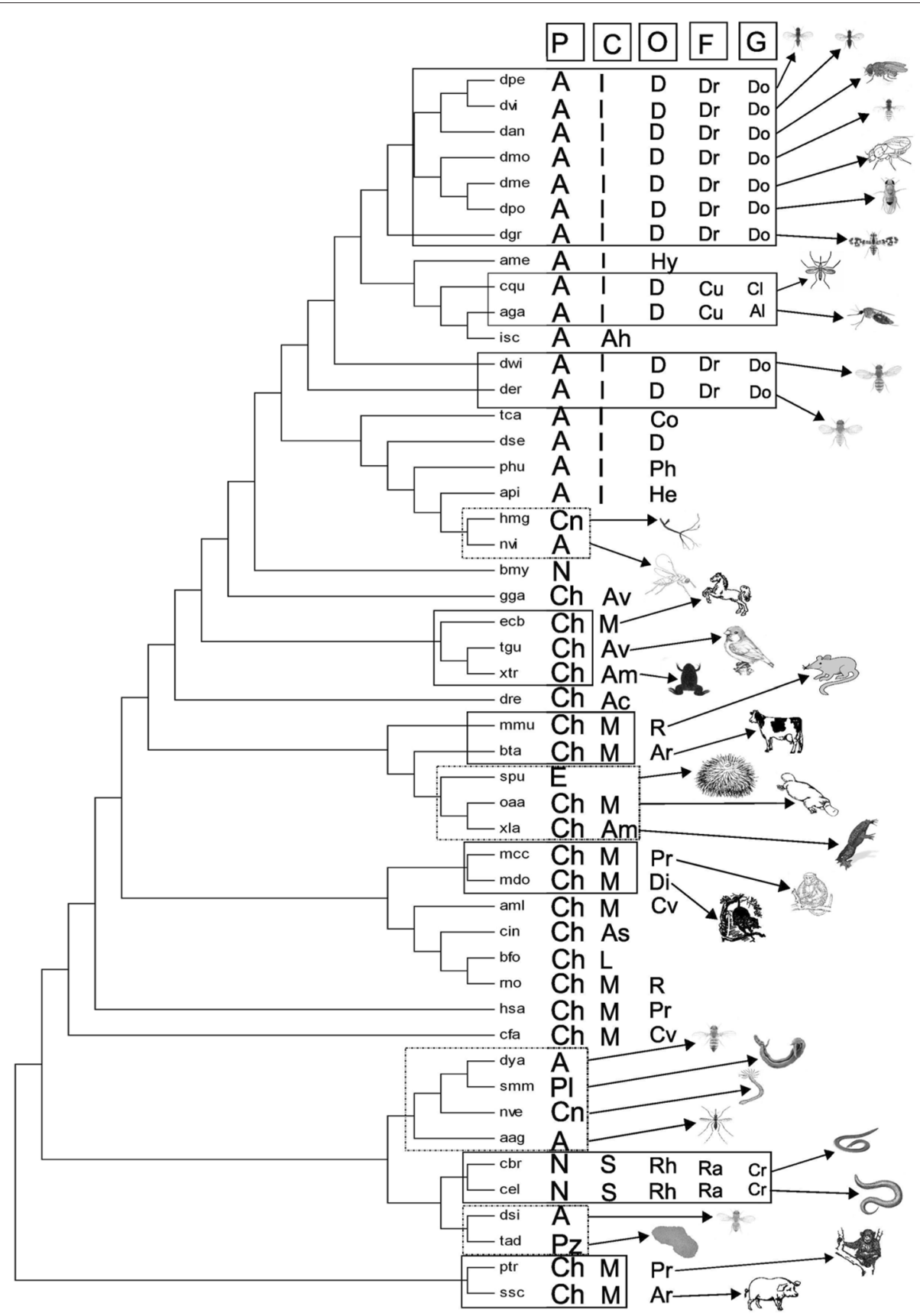

Fig. 5 The pathway tree. It is constructed from 48 species. The notations used in the figure are listed in Table 2

Their evolution spans approximately 600 million years of time [45].

The Wnt signal transduction pathway (STP) regulates various processes of metazoan development [44] and shows evolutionary conservation across a wide range of Metazoans $[45,46]$. Wnt STP is a combination of three pathways, i.e., canonical Wnt, planar cell polarity (PCP) and Wnt $/ \mathrm{Ca}^{2+}$ STPs. The canonical Wnt STP is more conserved across metazoan species than the others [46].
The PCP Wnt STP (first discovered in fruitfly) controls epithelial planar polarity within the eye, wing, and thorax $[47,48]$. It is well-conserved at molecular and functional levels throughout the bilaterian lineage [46]. The Wnt $/ \mathrm{Ca}^{2+}$ STP has been discovered in Xenopus and zebrafish $[49,50]$. But no equivalent pathway has been found in any other model system possibly making it a vertebrate-specific pathway. Emergence of metazoans appear to be linked with all the three STPs. These STPs 
Table 2 List of notations used in Figs. 4 and 5

\begin{tabular}{|c|c|c|c|c|c|}
\hline Notation & Rank & Name & Notation & Rank & Name \\
\hline$P$ & Phylum & - & $\mathrm{R}$ & Order & Rodentia \\
\hline A & Phylum & Arthropoda & $\operatorname{Ar}$ & Order & Artiodactyla \\
\hline $\mathrm{Cn}$ & Phylum & Cnidaria & $\mathrm{Pe}$ & Order & Perissodactyla \\
\hline N & Phylum & Nematoda & $\operatorname{Pr}$ & Order & Primates \\
\hline $\mathrm{Ch}$ & Phylum & Chordata & $\mathrm{Aa}$ & Order & Anura \\
\hline E & Phylum & Echinodermata & $\mathrm{Di}$ & Order & Didelmorphia \\
\hline $\mathrm{Pl}$ & Phylum & Platyhelminthes & CV & Order & Carnivora \\
\hline $\mathrm{Pz}$ & Phylum & Placozoa & $\mathrm{Rh}$ & Order & Rhabditida \\
\hline C & Class & - & $\mathrm{F}$ & Family & - \\
\hline I & Class & Insecta & Dr & Family & Drosophilidae \\
\hline Ah & Class & Arachnida & $\mathrm{Mu}$ & Family & Muridae \\
\hline Av & Class & Aves & $\mathrm{Pi}$ & Family & Pipidae \\
\hline $\mathrm{Am}$ & Class & Amphibia & $\mathrm{Cd}$ & Family & Canidae \\
\hline$A C$ & Class & Actinopterygii & U & Family & Ursidae \\
\hline M & Class & Mammalia & $\mathrm{Cu}$ & Family & Culicidae \\
\hline As & Class & Ascidiacea & Ra & Family & Rhabditidae \\
\hline L & Class & Leptocardii & G & Genus & - \\
\hline S & Class & Secernentea & Do & Genus & Drosophila \\
\hline $\mathrm{O}$ & Order & - & Ms & Genus & Mus \\
\hline $\mathrm{D}$ & Order & Diptera & Rt & Genus & Rattus \\
\hline Hy & Order & Hymenoptera & $x$ & Genus & Xenopus \\
\hline Mo & Order & Monotremata & $\mathrm{Ae}$ & Genus & Aedes \\
\hline Co & Order & Coleoptera & $\mathrm{Cl}$ & Genus & Culex \\
\hline $\mathrm{Ph}$ & Order & Phthiraptera & $\mathrm{Al}$ & Genus & Anophelinae \\
\hline $\mathrm{He}$ & Order & Hemiptera & $\mathrm{Cr}$ & Genus & Caenorhabditis \\
\hline
\end{tabular}

have been found well-conserved among a lot of metazoans, from cnidarians to vertebrates [46], based on the identification of their individual components.

\section{Placozoa}

They are the simplest in structure of all non-parasitic multicellular animals (Metazoa). They are generally classified as a single species, Trichoplax adhaerens. Components of a complete Wnt/ $\beta$-catenin STP associated with axial patterning of demosponge larvae [51], bilaterians and cnidarians [52] are present in Trichoplax [53].

\section{Cnidaria}

Cnidarians are the first metazoans with a defined adult body plan, main body axis, tissue level of organization and nervous system. They provide potential information regarding evolution of Wnt STP and its role in axis formation, polarity and germ-layer specification among others. Components of all the three Wnt STPs are present in cnidarians. They possess 14 Wnt orthologs $[54,55]$ of twelve distinct subfamilies including WntA whose human counterpart is absent. Multiple Wnt and Fzd genes have been found in Nematostella vectensis. So, expansion of

Table 3 Similarities among trees for 99, 48, 29 \& 12 species in percentage

\begin{tabular}{|c|c|c|c|c|c|c|c|c|}
\hline & \multicolumn{2}{|l|}{99 species } & \multicolumn{2}{|l|}{48 species } & \multicolumn{2}{|l|}{29 species } & \multicolumn{2}{|l|}{12 species } \\
\hline & $\begin{array}{l}\text { NCBI } \\
\text { Taxonomy tree }\end{array}$ & $\begin{array}{l}\text { 18S } \\
\text { rRNA tree }\end{array}$ & $\begin{array}{l}\text { NCBI } \\
\text { Taxonomy tree }\end{array}$ & $\begin{array}{l}18 S \\
\text { rRNA tree }\end{array}$ & $\begin{array}{l}\mathrm{NCBI} \\
\text { Taxonomy tree }\end{array}$ & $\begin{array}{l}18 \mathrm{~S} \\
\text { rRNA tree }\end{array}$ & $\begin{array}{l}\mathrm{NCBI} \\
\text { Taxonomy tree }\end{array}$ & $\begin{array}{l}18 \mathrm{~S} \\
\text { rRNA tree }\end{array}$ \\
\hline Module tree & 36.3 & 32.4 & 42.4 & 42.2 & 48.9 & 39 & 45.4 & 55.4 \\
\hline Pathway tree & 30.3 & 26.9 & 38.2 & 37.1 & 38.2 & 36.2 & 36.7 & 37.3 \\
\hline
\end{tabular}


Table 4 A list of 99 species-specific Wnt signaling pathways and their respective 18 S rRNA Reference ids

\begin{tabular}{|c|c|c|c|c|c|c|}
\hline $\begin{array}{l}\text { Sl. } \\
\text { No. }\end{array}$ & $\begin{array}{l}\text { KEGG } \\
\text { code }\end{array}$ & $\begin{array}{l}\text { Binomial } \\
\text { nomenclature }\end{array}$ & $\begin{array}{l}\text { Common } \\
\text { name }\end{array}$ & $\begin{array}{l}\text { No. of } \\
\text { genes }\end{array}$ & $\begin{array}{l}\text { No. of } \\
\text { modules }\end{array}$ & $\begin{array}{r}185 \text { rRNA } \\
\text { sequence id }\end{array}$ \\
\hline 1 & aag & A. aegypti & $\begin{array}{l}\text { Yellow fever } \\
\text { mosquito }\end{array}$ & 41 & 6 & U65375.1 [G] \\
\hline 2 & acs & A. carolinensis & Green anole & 61 & 9 & AY859624.1 [G-P] \\
\hline 3 & aec & A. echinatior & $\begin{array}{l}\text { Panamanian } \\
\text { leafcutter ant }\end{array}$ & 36 & 6 & AEVX01007365 [G-S] \\
\hline 4 & aga & A. gambiae & Mosquito & 39 & 6 & AM157179.1 [G] \\
\hline 5 & ame & A. mellifera & Honey bee & 43 & 7 & AB126807.1 [G-P] \\
\hline 6 & amj & A. mississippiensis & $\begin{array}{l}\text { American } \\
\text { alligator }\end{array}$ & 62 & 9 & AF173605.1 [G] \\
\hline 7 & aml & A. melanoleuca & Giant Panda & 62 & 9 & ACTA01092993 [G-S] \\
\hline 8 & api & A. pisum & Pea aphid & 42 & 8 & U27819.1 [G] \\
\hline 9 & apla & A. platyrhynchos & Mallard & 56 & 8 & AF173614.1 [G] \\
\hline 10 & aqu & A. queenslandica & Sponge & 32 & 6 & EF654521.1 [G-P] \\
\hline 11 & asn & A. sinensis & $\begin{array}{l}\text { Chinese } \\
\text { alligator }\end{array}$ & 59 & 9 & JX481969.1 [G-P] \\
\hline 12 & bacu & $\begin{array}{l}\text { B. acutorostrata } \\
\text { scammoni }\end{array}$ & Mink whale & 63 & 9 & ATDI01000034 [G-S] \\
\hline 13 & bfo & B. floridae & $\begin{array}{l}\text { Florida } \\
\text { lancelet }\end{array}$ & 42 & 7 & M97571.1 [G] \\
\hline 14 & bmor & B. mori & $\begin{array}{l}\text { Domestic } \\
\text { silkworm }\end{array}$ & 46 & 8 & DQ347470.1 [G] \\
\hline 15 & bmy & B. malayi & Filaria & 38 & 7 & AF036588.1 [G-P] \\
\hline 16 & bom & B. mutus & Wild yak & 63 & 9 & AGSK01136783 [G-S] \\
\hline 17 & bta & B. taurus & Cow & 63 & 9 & NR_036642.1 [G] \\
\hline 18 & $\mathrm{cbr}$ & C. briggsae & - & 31 & 5 & U13929.1 [G-P] \\
\hline 19 & cel & C. elegans & Nematode & 27 & 4 & NR_000054.1 [G] \\
\hline 20 & $\mathrm{cfa}$ & C. familiaris & Dog & 63 & 9 & AY623831.1 [G-P] \\
\hline 21 & cfo & C. floridanus & $\begin{array}{l}\text { Florida } \\
\text { carpenter ant }\end{array}$ & 42 & 7 & AEAB01019515 [G-S] \\
\hline 22 & cge & C. griseus & Chinese hamster & 63 & 9 & NR_045132.1 [G] \\
\hline 23 & $\operatorname{ch} x$ & C. hircus & Goat & 61 & 9 & DQ149973.1 [G-P] \\
\hline 24 & $\operatorname{cin}$ & C. intestinalis & Sea squirt & 42 & 7 & AB013017.1 [G-P] \\
\hline 25 & $\mathrm{cjc}$ & C. jacchus & $\begin{array}{l}\text { White tufted } \\
\text { ear marmoset }\end{array}$ & 62 & 9 & AB571241.1 [G-P] \\
\hline 26 & $\mathrm{clv}$ & C. livia & Rock pigeon & 56 & 8 & AF173630.1 [G] \\
\hline 27 & $\mathrm{cmk}$ & C. milii & Elephant shark & 58 & 8 & AY049813.1 [G] \\
\hline 28 & cqu & C. quinquefasciatus & $\begin{array}{l}\text { Southern house } \\
\text { mosquito }\end{array}$ & 41 & 6 & AAWU01003351 [G-S] \\
\hline 29 & $\mathrm{crg}$ & C. gigas & Pacific oyster & 45 & 8 & AB064942.1 [G] \\
\hline 30 & dan & D. ananassae & - & 42 & 7 & XR_046314.1[G] \\
\hline 31 & der & D. erecta & - & 43 & 7 & XR_046906.1 [G] \\
\hline 32 & dgr & D. grimshawi & - & 43 & 7 & {$[S-E]$} \\
\hline 33 & dme & D. melanogaster & Fruit fly & 42 & 7 & NR_133559.1 [G] \\
\hline 34 & dmo & D. mojavensis & - & 42 & 6 & XR_047783.1 [G] \\
\hline 35 & dpe & D. persimilis & - & 39 & 6 & XR_048244.1 [G] \\
\hline
\end{tabular}


Table 4 A list of 99 species-specific Wnt signaling pathways and their respective 18S rRNA Reference ids (Continuation)

\begin{tabular}{|c|c|c|c|c|c|c|}
\hline 36 & dpo & $\begin{array}{l}\text { D. pseudoobscura } \\
\text { pseudoobscura }\end{array}$ & - & 41 & 7 & XR_053284.1 [G] \\
\hline 37 & dre & D. rerio & Zebrafish & 63 & 9 & AC139725 [G-S] \\
\hline 38 & dse & D. sechellia & - & 42 & 7 & $X R \_048770.1[\mathrm{G}]$ \\
\hline 39 & dsi & D. simulans & - & 34 & 6 & AY037174.1 [G] \\
\hline 40 & dvi & D. virilis & - & 43 & 7 & XR_049279.1 [G] \\
\hline 41 & $d w i$ & D. willistoni & - & 43 & 7 & XR_049811.1 [G] \\
\hline 42 & dya & D. yakuba & - & 43 & 7 & AAEU02010701 [G-S] \\
\hline 43 & ecb & E. caballus & Horse & 62 & 9 & NR_046271.1 [G] \\
\hline 44 & fca & F. catus & Domectis cat & 62 & 9 & AY150542.1 [G-P] \\
\hline 45 & fch & F.cherrug & Saker falcon & 56 & 8 & AKMU01028905 [G-S] \\
\hline 46 & gga & G.gallus & Chicken & 57 & 9 & AF173612.1 [G] \\
\hline 47 & ggo & G. gorilla gorilla & $\begin{array}{l}\text { Western lowland } \\
\text { gorilla }\end{array}$ & 62 & 9 & CABD030100652 [G-S] \\
\hline 48 & hgl & H. glaber & Naked mole rat & 63 & 9 & AHKG01114378 [G-S] \\
\hline 49 & hmg & H. magnipapillata & - & 30 & 6 & ABRM01041397 [G-S] \\
\hline 50 & hro & H. robusta & - & 42 & 8 & AMQM01008875 [G-S] \\
\hline 51 & hsa & H. sapiens & Human & 63 & 9 & X03205.1[G] \\
\hline 52 & hst & H. saltator & $\begin{array}{l}\text { Jerdon's } \\
\text { jumping ant }\end{array}$ & 42 & 7 & AEAC01025389 [G-S] \\
\hline 53 & isc & I. scapularis & $\begin{array}{l}\text { Black-legged } \\
\text { tick }\end{array}$ & 44 & 8 & ABJB010537244 [G-S] \\
\hline 54 & $\mathrm{Icm}$ & L. chalumnae & Coelacanth & 61 & 9 & L11288.1 [G] \\
\hline 55 & $\lg i$ & L. gigantea & Owl limpet & 34 & 7 & FJ977632.1 [G-P] \\
\hline 56 & loa & L. $10 a$ & Eye worm & 41 & 8 & DQ094173.1 [G-P] \\
\hline 57 & Ive & L. vexillifer & $\begin{array}{l}\text { Yangtze River } \\
\text { dolphin }\end{array}$ & 63 & 9 & AUPI01105851 [G-S] \\
\hline 58 & mcc & M. mulatta & Rhesus Monkey & 62 & 9 & FJ436026 [G-P] \\
\hline 59 & mcf & M. fascicularis & Crab eating macaque & 63 & 9 & AB172927 [G-S] \\
\hline 60 & mde & M. domestica & House fly & 42 & 7 & GQ465780.1 [G-P] \\
\hline 61 & mdo & M. domestica & Opossum & 62 & 9 & AJ311676.1 [G-P] \\
\hline 62 & mgp & M. gallopavo & Turkey & 56 & 8 & AJ419877.1 [G] \\
\hline 63 & $\mathrm{mmu}$ & M. musculus & Mouse & 63 & 9 & NR_003278.3 [G] \\
\hline 64 & myb & M. brandtii & Brandt's bat & 61 & 9 & ANKR01250841 [G-S] \\
\hline 65 & myd & M. davidii & - & 61 & 9 & ALWT01111512 [G-S] \\
\hline 66 & mze & M. zebra & Zebra mbuna & 61 & 9 & GBAN01001852 [G-S] \\
\hline 67 & ngi & N. galili & $\begin{array}{l}\text { Upper Galilee } \\
\text { mountains blind } \\
\text { mole rat }\end{array}$ & 63 & 9 & JO020273 [G-S] \\
\hline 68 & nle & N. leucogenys & $\begin{array}{l}\text { Northern white } \\
\text { cheeked gibbon }\end{array}$ & 63 & 9 & ADFV01131837 [G-S] \\
\hline 69 & nve & N. vectensis & Sea anemone & 30 & 6 & AF254382.1 [G] \\
\hline 70 & nvi & N. vitripennis & Jewel wasp & 42 & 7 & GQ410677.1 [G-P] \\
\hline 71 & oaa & O. anatinus & Platypus & 54 & 8 & AJ311679.1 [G-P] \\
\hline 72 & oas & O. aries & Sheep & 63 & 9 & AY753190.1 [G-P] \\
\hline 73 & ocu & O. cuniculus & Rabbit & 63 & 9 & NR_033238.1 [G] \\
\hline 74 & ola & O. latipes & Japanese medaka & 59 & 9 & AB105163.1 [G] \\
\hline 75 & pale & P. alecto & Black flying fox & 63 & 9 & ALWS01159237 [G-S] \\
\hline
\end{tabular}


Table 4 A list of 99 species-specific Wnt signaling pathways and their respective 18 S rRNA Reference ids (Continuation)

\begin{tabular}{|c|c|c|c|c|c|c|}
\hline 76 & phd & P. hodgsonii & Chiru & 61 & 9 & AGTT01252085 [G-S] \\
\hline 77 & phu & $\begin{array}{l}\text { P. humanus } \\
\text { corporis }\end{array}$ & $\begin{array}{l}\text { Human body } \\
\text { louse }\end{array}$ & 41 & 7 & AF139482.1 [G-P] \\
\hline 78 & pon & P. abelii & $\begin{array}{l}\text { Sumatran } \\
\text { orangutan }\end{array}$ & 63 & 9 & ABGA01173767 [G-S] \\
\hline 79 & pps & P.paniscus & Bonobo & 63 & 9 & AJFE01002621 [G-S] \\
\hline 80 & pss & P. sinensis & $\begin{array}{l}\text { Chinese soft } \\
\text { shelled turtle }\end{array}$ & 60 & 9 & JX481969.1 [G-P] \\
\hline 81 & ptr & P. troglodytes & Chimpanzee & 63 & 9 & AADA01153094 [G-S] \\
\hline 82 & pxy & P.xylostella & Diamondback moth & 32 & 5 & JX390653.1 [G-P] \\
\hline 83 & rno & R. norvegicus & Rat & 63 & 9 & NR_046237.1 [G] \\
\hline 84 & rro & R. roxellana & $\begin{array}{l}\text { Golden snub } \\
\text { nosed monkey }\end{array}$ & 63 & 9 & JABR01093782 [G-S] \\
\hline 85 & shr & S. harrisii & Tasmanian devil & 61 & 9 & AFEY01231219 [G-S] \\
\hline 86 & $\mathrm{smm}$ & S.mansoni & - & 26 & 4 & M62652.1 [G] \\
\hline 87 & soc & S. invicta & Red fire ant & 43 & 7 & AY334566.1 [G-P] \\
\hline 88 & spu & S. purpuratus & $\begin{array}{l}\text { Purple } \\
\text { sea urchin }\end{array}$ & 46 & 6 & L28056.1 [G] \\
\hline 89 & SSC & S. scrofa & Pig & 62 & 9 & AY265350.1 [G] \\
\hline 90 & tad & T. adhaerens & - & 26 & 5 & ABGP01001110 [G-S] \\
\hline 91 & tca & T. castaneum & $\begin{array}{l}\text { Red flour } \\
\text { beetle }\end{array}$ & 43 & 7 & HM156711.1 [G-P] \\
\hline 92 & $\operatorname{tg} u$ & T. guttata & Zebra finch & 56 & 8 & ABQF01063677 [G-S] \\
\hline 93 & tru & T.rubripes & Torafugu & 60 & 9 & AB437886.1 [G-P] \\
\hline 94 & tsp & T. spiralis & - & 39 & 8 & AY497012.1 [G-P] \\
\hline 95 & tup & T. chinensis & Chinese tree shrew & 62 & 9 & ALAR01203917 [G-S] \\
\hline 96 & umr & U.maritimus & Polar bear & 60 & 9 & AVOR01047284 [G-S] \\
\hline 97 & xla & X. laevis & $\begin{array}{l}\text { African } \\
\text { clawed frog }\end{array}$ & 54 & 9 & X04025.1 [G] \\
\hline 98 & xma & X.maculatus & Southern platyfish & 59 & 9 & KJ774770.1 [G-P] \\
\hline 99 & $x \operatorname{tr}$ & X. tropicalis & $\begin{array}{l}\text { Western } \\
\text { clawed frog }\end{array}$ & 60 & 9 & AAMC02038921 [G-S] \\
\hline
\end{tabular}

Notations: G: GenBank accession number (Complete sequence), G-P: GenBank accession number (Partial Sequence), G-S: GenBank accession number of predicted 18S rRNA sequence as given in SILVA database (Pruesse et al. 2007), S-E: Sequence taken from (Stage and Eickbush 2007)

these gene families must have occurred in early evolution. Out of total 13 Wnt sub-families, 12 have been retained in this species [56], while Wnt9 gene is not found. The large inventory of Wnt genes in Nematostella indicates diversification of this gene family in the cnidarian-bilaterian ancestor [44].

\section{Platyhelminthes}

Flatworms have a highly reduced and dispersed complement of Wnt STP. It includes orthologs of Wnt1, Wnt2, Wnt4, Wnt5 and Wnt11 subfamilies and a few paralogs in parasitic flatworms (5/6 genes). All the antagonists, receptors and key binding domains of Wnt STP are intact in this phylum indicating functional status of the canonical (Wnt/ $\beta$-catenin) and non-canonical (PCP and
Wnt/Ca ${ }^{2+}$ ) STPs. Evolution of flatworms appears to be associated with loss of Wnt6, Wnt7, Wnt8, Wnt9, Wnt10, Wnt16 and WntA subfamilies. Moreover, loss of Wnt4 paralogs is associated with the evolution of parasitism in this phylum [57].

It was found through in silico approaches that the Hymenolepis microstoma genome contains a total of six Wnt genes, representing five subfamilies, i,e., Hm-Wnt1, Hm-Wnt2, Hm-Wnt4, Hm-Wnt5 and Hm-Wnt11a/b]. Other down-stream members are also present, i.e., HmfzdB and Hm-dsh; Hm-Bcat; Hm-TCF/LEF. In Schisostoma mansoni, single orthologs of Wnt1, Wnt2 and Wnt5 and two paralogs of Wnt11a are present, but Wnt11b is absent. The species Schmidtea mediterranea possesses three paralogs of Wnt4, while other parasitic flatworms 
possess only one [57]. However, these results are yet to be experimentally validated.

\section{Nemathelminthes}

Both the canonical and noncanonical Wnt STPs exist in C. elegans. Its genome has five genes for Wnt ligands, four genes for Fzd receptors and one gene for Ryk/Derailed $[56,58,59]$. Unlike vertebrates or arthropods, the C. elegans genome has three $\beta$-catenin genes (WRM- 1 , BAR- 1 and HMP-2). They have clearly demarcated functions in signaling and cell adhesion [60]. BAR-1 is a part of the canonical Wnt STP while WRM-1 is part of the noncanonical Wnt STP [59].

\section{Arthropoda}

Arthropods are characterized by the loss of Wnt16 [57, 61]. Tribolium castaneum (beetle) of Ecdysozoa super-phylum has only nine subfamilies, with no duplications [56, 58]. Drosophila melanogaster has just seven Wnt genes [56].

\section{Echinodermata}

This phylum offers insights into the earliest and the most basic of the deuterostome animals [54]. The Strongylocentrotus purpuratus (sea urchin) genome reveals many deuterostome-like properties. It contains genes that are absent in the more derived deuterostomes. On the contrary these particular genes are found to be present in cnidaria and/or protostomia. Hence this phylum exhibits Wnt genes present in the lower as well as higher phyla, becoming a probable link among them.

Sea urchin has eleven of the thirteen reported Wnt subfamilies along with a WntA ortholog (SpWntA) thought to be absent in deuterostomes. WntA proteins are presents in cnidarians, ecdysozoans and lophotrochozoans but have not been reported in any chordate lineage to date. From these findings, it appears that the WntA subfamily was present in the common ancestor of deuterostomes, but apparently was lost during chordate evolution [54]. Wnt2 and Wnt11 genes are absent. Loss of the Wnt-2 ortholog in Metazoa is quite an uncommon event. However, the absence of Wnt-11 is frequently encountered.

\section{Chordata}

Chordates are characterized by the loss of WntA. They are also known for presence of a large number of Wnt paralogs and associated downstream components [62]. Multiple Wnt antagonists, such as DKK, CER, Wnt Inhibitory Factor (WIF) and Secreted Frizzled Related Protein (SFRP) are reported in vertebrates. Evolution of complexity in Wnt signaling is probably catalyzed by the Wnt antagonists. By comparison, a few Wnt antagonists are found in basal Metazoa [43, 57]. The human genome of super-phylum Deuterostomia has 19 Wnt genes. These genes belong to Wnt1 to Wnt11, and Wnt16
$[54,63]$ subfamilies (12 subfamilies) with seven duplications $[56,62]$.

\section{Wnt Evolution and the Module tree}

Wnt genes and the associated pathway (Wnt signaling pathway) show varied characteristics starting from placozoa (Trichoplax adherens) to chordata (H. sapiens). A complete component of Wnt signaling pathway is present in Trichoplax, irrespective of its simple body plan that presumably takes part in other functions [51-53]. The Wnt diversity continues to cnidarians which flaunt a defined body-plan indicating use of the Wnt signaling pathway. They possess $14 \mathrm{Wnt}$ orthologs belonging to 12 sub-families. An additional WntA is present which do not have any human counter-part $[44,54,55]$. This diversity of Wnt genes is lost in flatworms. They possess only five sub-families of Wnts, but both the canonical and non-canonical Wnt signaling pathways are found to be functional. Wnt6-Wnt10, Wnt16 and WntA genes are lost. In addition, the Wnt 4 gene is lost with rise of parasitism [57], which is probably due to easy access to the genetic machinery of the host organism.

Nematodes have only 5 Wnt ligands and flaunt more super-specialization in the form of three distinct $\beta$-catenin genes with distinct separate functionality [56, 58-60]. Arthropods are characterized by the loss of Wnt16 [57, 61]. The beetle T. castaneum (super-phylum Ecdysozoa) retains only 9 Wnt subfamilies, with no duplications $[56,58]$ while D. melanogaster (fruitfly) has just 7 Wnt genes [56]. Echinoderms retain 11 sub-families of Wnt genes with a WntA ortholog, indicating their connection with protostomes. Wnt2 and Wnt11 genes are absent. While absence of Wnt11 is quite common in other metazoans, absence of Wnt2 is an exception [54]. Chordates are characterized by their complexity in Wnt signaling, presence of multiple Wnt antagonists and loss of WntA gene. Humans have 19 Wnt genes, representing 12 subfamilies with seven duplications $[56,62]$.

These observations indicate a possible gene duplication event in MRCA 940 Mya (Million years ago) that continued to placozoans in a subdued manner, then lost in Platyhelminthes and Nemathelminthes. The loss is minimized in Arthropods possibly due to a gene-boom during or before divergence of Echinoderms $\sim 500$ Mya. Echinoderms retain a mixture of old and new Wnt characteristics that flourish extensively in Chordates with loss of early Protostome characteristics $[16,64]$. Presumably amidst multiple gene duplication events, the Wnt genes pass through a wormhole-like phase; wormholes being a hypothetical topological feature of space time as given in Fig. 6. Although the gene duplication events do not correlate with the origin of the principal animal groups, they can be related to evolutionary course of Wnt gene family. 


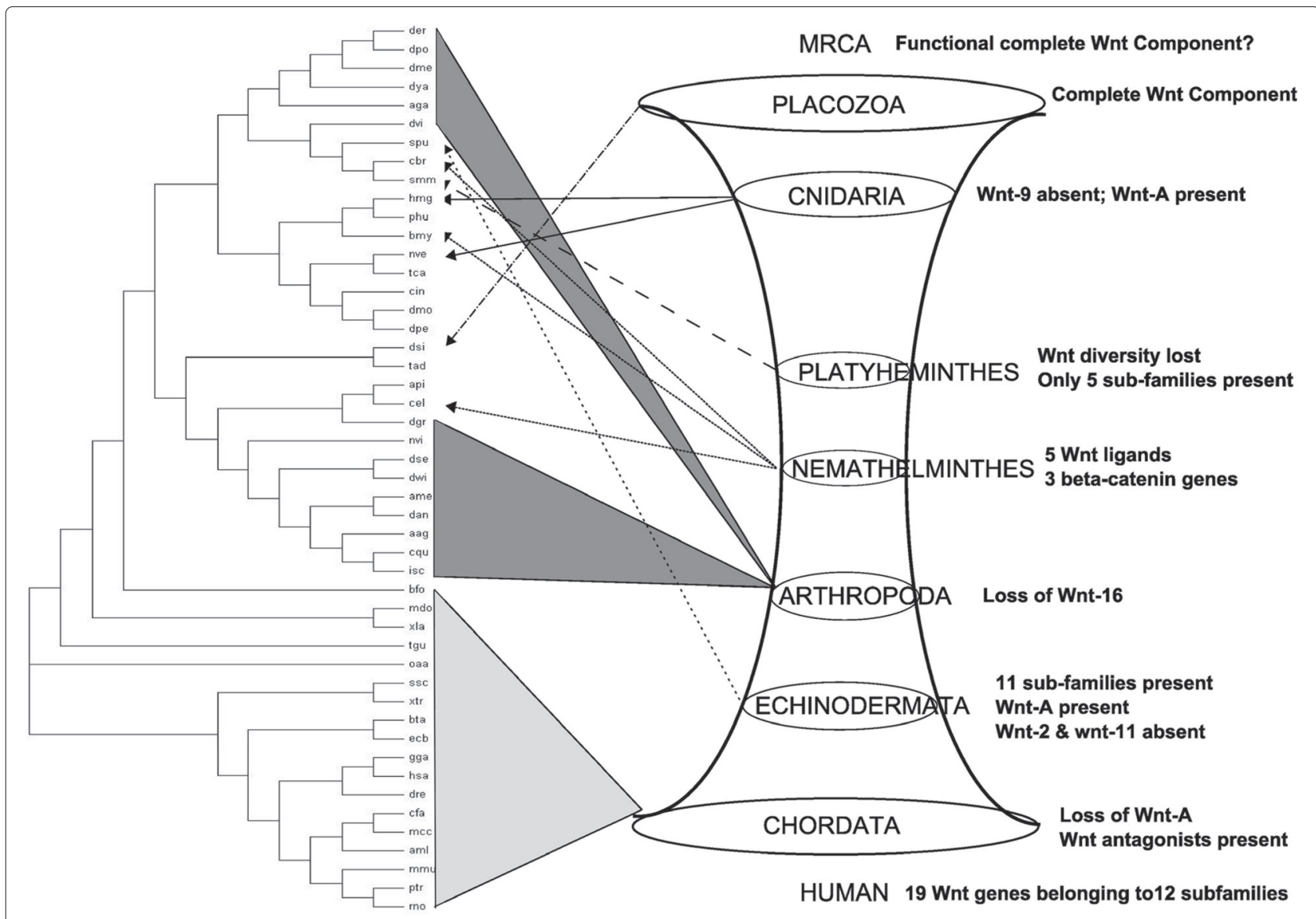

Fig. 6 Relational aspects between module tree and Wnt signaling pathway evolution. Interestingly, Wnt genes pass through a wormhole like phase in time during evolution

When the module tree is compared with this emerging pattern of Wnt gene family evolution (Fig. 6), we have found that most of the chordates were placed in vicinity of each other, except a few. Arthropods formed two distinct clusters. Placing of the only placozoan (tad), platyheminth (smm) and echinoderm (spu) cannot be commented upon due to their singular presence in the species set. Still placing of the single platyheminth (smm) with a nematode (cbr) is justifiable from the fact that species from both the phyla tolerate Wnt diversity loss. The two cnidarians (hmg and nve) are closely placed with the echinoderm (spu) probably based on their similarity of having WntA gene. The Phyla Chordata and Arthropoda are quite diverse from speciation point of view. A more compact and individual study of species of these phyla will bring more conclusive facts about Wnt signaling pathway evolution in these phyla, and may also describe the unexplained positioning of some species in the module tree.

\section{Conclusions}

This article emphasized on development of Wnt STP over various species. Here, we have created two alternate phylogenetic trees, i.e., the pathway and module trees from four species sets of species-specific pathways (comprising 99, 48, 29 and 12 species), and compared them with two reference trees (the NCBI taxonomy tree and the 18S rRNA tree). The module tree is found to be more similar to the reference trees than the pathway tree. Hence the module tree is a better candidate to represent Wnt STP development. The increased performance of the module tree is due to consideration of local similarities, which probably we ignore in a global scenario. This concept of taking modules/sub-units/sub-sets of pathways (local information) in to construction of a phylogenetic tree rather than considering the whole pathways (global information) can be extended to other fields of phylogenetic analysis.

Moreover, the module tree has been linked with the major events that happened in course of Wnt gene family evolution. However, there are some species-arrangements in the module tree which defy the general notion of taxonomy and evolution. This may turn out to be the pressure of speciation that the phyla faced individually and originates scopes for further phylum specific research and analysis. 


\section{Additional file}

Additional file 1: It is a '.zip' file containing the four figures for NCBI taxonomy, 18S rRNA, pathway and module trees for 99 species-specific Wnt STPs. Moreover, a text file titled, "the_final_trees_newick_format.txt" is provided with the newick format of these trees. (ZIP $253 \mathrm{~kb}$ )

\section{Acknowledgements}

LN acknowledges University Grants Commission, India for a UGC Post-Doctoral Fellowship (No. F.15-1/2013-14/PDFWM-2013-14-GE-ORI-19068(SA-II)).

\section{Declarations}

This article has been published as part of BMC Systems Biology Vol 10 Suppl 2 2016: Selected articles from the IEEE International Conference on Bioinformatics and Biomedicine 2015: systems biology. The full contents of the supplement are available online at http://bmcsystbiol.biomedcentral.com/ articles/supplements/volume-10-supplement-2.

\section{Funding}

Publication of this article was funded by University Grants Commission, India and Indian Statistical Institute, India.

\section{Authors' contributions}

LN conceptualized the work and conducted the experiments. NPB gave crucial theoretical input to the work. Both LN and RKD read the manuscript and corrected it.

\section{Competing interests}

The authors declare that they have no competing interests.

\section{Author details}

${ }^{1}$ Indian Statistical Institute, 203 Barrackpore Trunk Road, 700108 Kolkata, India. ${ }^{2}$ Saha Institute of Nuclear Physics, 1/AF Bidhan Nagar, 700064 Kolkata, India. ${ }^{3}$ Present Affiliation: Biomedical Genomics Centre, 5 Suburban Hospital Road, 700020 Kolkata, India.

\section{Published: 1 August 2016}

\section{References}

1. Cadigan KM, Liu YI. Wnt signaling: complexity at the surface. J Cell Sci. 2006;119(3):395-402.

2. Nusse R, Varmus H. Three decades of Wnts: a personal perspective on how a scientific field developed. EMBO J. 2012;31(12):2670-84.

3. Moon RT, Shah K. Developmental biology: Signalling polarity. Nature. 2002;417(6886):239-40.

4. Willert K, Brown JD, Danenberg E, Duncan AW, Weissman IL, Reya T, Yates JR, Nusse R. Wnt proteins are lipid-modified and can act as stem cell growth factors. Nature. 2003;423(6938):448-52.

5. Pinto D, Clevers H. Wnt, stem cells and cancer in the intestine. Biol Cell. 2005;97(3):185-96.

6. Lowry W, Blanpain C, Nowak J, Guasch G, Lewis L, Fuchs E. Defining the impact of beta-catenin/Tcf transactivation on epithelial stem cells. Genes Dev. 2005;19(13):1596-611.

7. Reya T, Duncan AW, Ailles L, Domen J, Scherer DC, Willert K, Hintz L, Nusse R, Weissman IL. A role for Wnt signalling in self-renewal of haematopoietic stem cells. Nature. 2003;423(6938):409-14.

8. Polesskaya A, Seale P, Rudnicki MA. Wnt signaling induces the myogenic specification of resident CD45+ adult stem cells during muscle regeneration. Cell. 2003;113(7):841-52.

9. Stoick-Cooper CL, Weidinger G, Riehle KJ, Hubbert C, Major MB, Fausto $\mathrm{N}$, Moon RT. Distinct Wnt signaling pathways have opposing roles in appendage regeneration. Development. 2007;134(3):479-89.

10. Fathke C, Wilson L, Shah K, Kim B, Hocking A, Moon R, Isik F. Wnt signaling induces epithelial differentiation during cutaneous wound healing. BMC Cell Biology. 2006;7(1):4.

11. Zhang D, Gu L, Liu L, Wang C, Sun B, Li Z, Sung C. Effect of Wnt signaling pathway on wound healing. Biochem Biophys Res Commun. 2009;378(2):149-51.
12. Lewandowski J, Kolanowski TJ, Kurpisz M. Techniques for the induction of human pluripotent stem cell differentiation towards cardiomyocytes. J Tissue Eng Regen Med. 2016;1-16. doi:10.1002/term.2117.

13. Félix MA. An inversion in the wiring of an intercellular signal: evolution of wnt signaling in the nematode vulva. BioEssays. 2005;27(8):765-9.

14. Hendriks $B$, Reichmann E. Wnt signaling: a complex issue. Biol Res. 2002;35(2):277-86.

15. Janssen R, Le Gouar M, Pechmann M, Poulin F, Bolognesi R, Schwager EE, Hopfen C, Colbourne JK, Budd GE, Brown SJ, et al. Conservation, loss, and redeployment of Wnt ligands in protostomes: implications for understanding the evolution of segment formation. BMC Evol Biol. 2010;10(1):374.

16. Pires-daSilva A, Sommer RJ. The evolution of signalling pathways in animal development. Nat Rev Genet. 2003;4(1):39-49.

17. Holstein TW. The evolution of the Wnt pathway. Cold Spring Harbor Perspect Biol. 2012;4(7):007922.

18. Nayak $L$, De RK. An algorithm for modularization of MAPK and calcium signaling pathways: Comparative analysis among different species. J Biomed Informa. 2007;40(6):726-49.

19. Nayak L, De RK. Developmental trend derived from modules of Wnt signaling pathways. In: Pattern Recognition and Machine Intelligence. Berlin Heidelberg: Springer; 2011. p. 400-5.

20. Nayak L, Bhattacharyya NP, De RK. A module tree of wnt signal transduction pathways. In: 2015 IEEE International Conference on Bioinformatics and Biomedicine (BIBM). Washington DC, USA: IEEE; 2015. p. 43-8.

21. Kuchaiev O, Milenković T, Memišević V, Hayes W, Pržulj N. Topological network alignment uncovers biological function and phylogeny. J R Soc Interface. 2010;7(50):1341-54

22. Pinter RY, Rokhlenko O, Yeger-Lotem E, Ziv-Ukelson M. Alignment of metabolic pathways. Bioinforma. 2005;21(16):3401-408.

23. Forst CV, Schulten K. Phylogenetic analysis of metabolic pathways. J Mol Evol. 2001;52(6):471-89

24. Kelley BP, Yuan B, Lewitter F, Sharan R, Stockwell BR, Ideker T. PathBLAST: a tool for alignment of protein interaction networks. Nucleic Acids Res. 2004;32(suppl 2):83-8.

25. Ovacik MA, Androulakis IP. Enzyme sequence similarity improves the reaction alignment method for cross-species pathway comparison. Toxicol Appl Pharmacol. 2013;271(3):363-71.

26. Hariharaputran S, Töpel T, Oberwahrenbrock T, Hofestädt R. Alignment of linear biochemical pathways using protein structural classification. Nature Precedings. 2008.

27. Heymans M, Singh AK. Deriving phylogenetic trees from the similarity analysis of metabolic pathways. Bioinformatics. 2003;19(suppl 1):138-46.

28. Ali W, Deane CM. Functionally guided alignment of protein interaction networks for module detection. Bioinformatics. 2009;25(23):3166-73.

29. Clemente JC, Satou K, Valiente G. Reconstruction of phylogenetic relationships from metabolic pathways based on the enzyme hierarchy and the gene ontology. Genome Informa Ser. 2005;16(2):45.

30. Tohsato Y, Nishimura Y. Metabolic pathway alignment based on similarity between chemical structures. Informa Media Technol. 2008;3(1):191-200.

31. Ay F, Kellis M, Kahveci T. SubMAP: aligning metabolic pathways with subnetwork mappings. J Comput Biol. 2011;18(3):219-35.

32. Liao L, Kim S, Tomb JF. Genome comparisons based on profiles of metabolic pathways. In: Proceedings of the 6th International Conference on Knowledge-Based Intelligent Information and Engineering Systems (KES'02). Crema, Italy: IOS Press; 2002. p. 469-76.

33. Kanehisa M, Goto S. KEGG: kyoto encyclopedia of genes and genomes. Nucleic Acids Res. 2000;28(1):27-30.

34. Pruesse E, Quast C, Knittel K, Fuchs BM, Ludwig W, Peplies J, Glöckner FO. SILVA: a comprehensive online resource for quality checked and aligned ribosomal RNA sequence data compatible with ARB. Nucleic Acids Res. 2007:35(21):7188-96.

35. Stage DE, Eickbush TH. Sequence variation within the rRNA gene loci of 12 Drosophila species. Genome Res. 2007;17(12):1888-97.

36. Tamura K, Dudley J, Nei M, Kumar S. MEGA4: molecular evolutionary genetics analysis (MEGA) software version 4.0. Mole Biol Evol. 2007;24(8): 1596-9.

37. Benson DA, Cavanaugh M, Clark K, Karsch-Mizrachi I, Lipman DJ, Ostell J, Sayers EW. GenBank. Nucleic Acids Res. 2013;41(D1):D36-D42.

38. Kuchaiev O, Stevanović A, Hayes W, Pržulj N. GraphCrunch 2: software tool for network modeling, alignment and clustering. BMC Bioinforma. $2011 ; 12(1): 24$ 
39. Saitou N, Nei M. The neighbor-joining method: a new method for reconstructing phylogenetic trees. Mole Biol Evol. 1987;4(4):406-25.

40. Tamura $K$, Nei M, Kumar S. Prospects for inferring very large phylogenies by using the neighbor-joining method. Proc Natl Acad Sci USA. 2004;101(30):11030-35.

41. Federhen S. The NCBI taxonomy database. Nucleic Acids Res. 2012;40(D1): $136-43$.

42. Nye TM, Lio P, Gilks WR. A novel algorithm and web-based tool for comparing two alternative phylogenetic trees. Bioinformatics. 2006;22(1): $117-9$.

43. Pang K, Ryan JF, Mullikin JC, Baxevanis AD, Martindale MQ, et al. Genomic insights into wnt signaling in an early diverging metazoan, the ctenophore mnemiopsis leidyi. EvoDevo. 2010;1(1):10-10.

44. Lee PN, Pang K, Matus DQ, Martindale MQ. A WNT of things to come: evolution of Wnt signaling and polarity in cnidarians. In: Seminars in Cell \& Developmental Biology, vol. 17; 2006. p. 157-67.

45. van Amerongen $R$, Berns A. Knockout mouse models to study Wnt signal transduction. TRENDS in Genetics. 2006;22(12):678-89.

46. Croce JC, McClay DR. Evolution of the Wnt pathways. In: Wnt Signaling. New York, USA: Springer; 2009. p. 3-18.

47. Mlodzik M. Planar polarity in the Drosophila eye: a multifaceted view of signaling specificity and cross-talk. EMBO J. 1999;18(24):6873-79.

48. Adler PN, Lee H. Frizzled signaling and cell-cell interactions in planar polarity. Curr Opin Cell Biol. 2001;13(5):635-40.

49. Kühl M, Sheldahl LC, Malbon CC, Moon RT.

$\mathrm{Ca} 2+/$ calmodulin-dependent protein kinase II is stimulated by Wnt and Frizzled homologs and promotes ventral cell fates in Xenopus. J Biol Chem. 2000;275(17):12701-11.

50. Sheldahl LC, Park M, Malbon CC, Moon RT. Protein kinase C is differentially stimulated by wnt and frizzled homologs in a G-protein-dependent manner. Curr Biol. 1999;9(13):695-1.

51. Adamska M, Degnan SM, Green KM, Adamski M, Craigie A, Larroux C, Degnan BM. Wnt and TGF-beta expression in the sponge Amphimedon queenslandica and the origin of metazoan embryonic patterning. PLoS ONE. 2007;2(10):1031-1031.

52. Lee $\mathrm{PN}$, Kumburegama $\mathrm{S}$, Marlow $\mathrm{HQ}$, Martindale MQ, Wikramanayake AH. Asymmetric developmental potential along the animal-vegetal axis in the anthozoan cnidarian, Nematostella vectensis, is mediated by Dishevelled. Dev Biol. 2007;310(1):169-86.

53. Srivastava M, Begovic E, Chapman J, Putnam NH, Hellsten U, Kawashima T, Kuo A, Mitros T, Salamov A, Carpenter ML, et al. The Trichoplax genome and the nature of placozoans. Nature. 2008;454(7207):955-60.

54. Croce JC, Wu SY, Byrum C, Xu R, Duloquin L, Wikramanayake AH, Gache C, McClay DR. A genome-wide survey of the evolutionarily conserved Wnt pathways in the sea urchin Strongylocentrotus purpuratus. Dev Biol. 2006;300(1):121-31.

55. Kusserow A, Pang K, Sturm C, Hrouda M, Lentfer J, Schmidt HA, Technau U, von Haeseler A, Hobmayer B, Martindale MQ, et al. Unexpected complexity of the Wnt gene family in a sea anemone. Nature. 2005;433(7022):156-60.

56. Cho SJ, Valles Y, Giani VC, Seaver EC, Weisblat DA. Evolutionary dynamics of the wnt gene family: a lophotrochozoan perspective. Mole Biol Evol. 2010;27(7):1645-58.

57. Riddiford N, Olson PD. Wnt gene loss in flatworms. Dev Genes Evol. 2011;221(4):187-97.

58. Bolognesi R, Farzana L, Fischer TD, Brown SJ. Multiple Wnt genes are required for segmentation in the short-germ embryo of Tribolium castaneum. Curr Biol. 2008;18(20):1624-29.

59. Eisenmann DM. Wnt signaling. WormBook. 2005;25:1-17.

60. Herman MA. Wnt signaling in C. elegans. In: Wnt Signaling in Development. Georgetown, USA: Landes Biosciences; 2003. p. 187-212.

61. Murat S, Hopfen C, McGregor AP. The function and evolution of Wnt genes in arthropods. Arthropod Struct Dev. 2010;39(6):446-52.

62. Garriock RJ, Warkman AS, Meadows SM, D'Agostino S, Krieg PA. Census of vertebrate Wnt genes: isolation and developmental expression of Xenopus Wnt2, Wnt3, Wnt9a, Wnt9b, Wnt10a, and Wnt16. Dev Dyn. 2007;236(5):1249-58.

63. Miller JR. The wnts. Genome Biol. 2002;3(1):1-15.

64. Miyata T, Suga H. Divergence pattern of animal gene families and relationship with the Cambrian explosion. Bioessays. 2001;23(11):1018-27.

\section{Submit your next manuscript to BioMed Central and we will help you at every step:}

- We accept pre-submission inquiries

- Our selector tool helps you to find the most relevant journal

- We provide round the clock customer support

- Convenient online submission

- Thorough peer review

- Inclusion in PubMed and all major indexing services

- Maximum visibility for your research

Submit your manuscript at www.biomedcentral.com/submit 